\title{
MOTHERS EXPERIENCE WITH LOW BORN WEIGHT INFANT: A SCOOPING REVIEW
}

\author{
Yayu Yuliarti, Nurul Kurniati
}

Universitas ‘Aisyiyah Yogyakarta

\begin{abstract}
Background: Low Birth Weight (LBW) as babies born weighing less than 2500 grams. LBW continues to be a significant public health problem globally due to its short and long term effects on health. LBW is not the only leading cause of prenatal mortality and a cause of illness. Common causes of infant and neonatal mortality are low birth weight (LBW) and sepsis. One of the measures that can be given to babies with LBW is by using the Kangaroo Mother Care (KMC) method. This method is a free therapy that mothers can do because not all LBW babies are able to get health services using advanced technology. This study aimed to review mothers experience with low born weight infant.

Subjects and Method: A scoping review was conducted by searching articles published from 2009 to 2019. The articles were collected based on 4 databases, including PubMed, Sciencedirect, Wiley, and EBSCO. The articles the reviewed using Preferred Reporting System for Systematic Review and Meta-Analysis (PRISMA) flow diagram.

Results: Fifteen of the 394 articles met the inclusion criteria and were reviewed. The experience of mothers with Low Birth Weight (LBW) babies showed that mothers have several factors that can influence mothers with babies with LBW. The factors were lack of knowledge, lack of support from both family and health personnel, access to health facilities, maternal psychology, economic, socio-cultural, and environmental conditions.

Conclusion: The readiness of maternal, psychological, socio-economic knowledge, access to health facilities, support, socio-culture, and environment are greatly affect the condition of the mother in carrying out her responsibilities as a mother.
\end{abstract}

Keywords: mother's experience, low born weight, infant, scooping review

\section{Correspondence:}

Yayu Yuliarti. 'Aisyiyah University Yogyakarta. Jl. Ringroad Barat No.63, Mlangi, Nogotirto, Gamping Sleman, Yogyakarta. Email: yayuyuliartiaryo89@gmail.com. Mobile: 081350155401 